\title{
Experimental Investigation of the Hybrid FRP-UHPC-Steel Double-Skin Tubular Columns under Lateral Impact Loading
}

\author{
Weiqiang Wang, M.ASCE${ }^{1}$; Chengqing Wu²; Zhongxian $\mathrm{Liu}^{3}$; Kaixuan $\mathrm{An}^{4}$; and Jun-Jie Zeng, M.ASCE ${ }^{5}$
}

\begin{abstract}
The lateral impact behavior of hybrid fiber-reinforced polymer (FRP)-ultrahigh-performance concrete (UHPC)-steel double-skin tubular columns (DSTCs) was experimentally investigated in this study. Seven specimens, which had an outer diameter of $168 \mathrm{~mm}$ and a length of 2,000 mm, were tested under lateral impact loading. Different parameters, including the axial force level, impact energy, concrete type, void ratio, FRP tube thickness, and the presence/absence of the FRP tube, were investigated. The dynamic responses, including global/ local damage modes, lateral deflection-time histories, impact force-time histories, strain-time histories, and acceleration-time histories, were investigated. The test results prove that the hybrid UHPC DSTCs exhibit very ductile behavior under lateral impact loading. The hybrid UHPC DSTCs have a higher lateral impact resistance capacity as compared to the hybrid DSTCs infilled with normal-strength concrete. The lateral impact resistance capacity of hybrid UHPC DSTCs with an applied axial force of $200 \mathrm{kN}$ can be improved to some extent compared with those without any axial force. The impact energy, the void ratio, the FRP tube thickness, and the presence/absence of the FRP tube can significantly affect the lateral impact behavior of hybrid UHPC DSTCs. Furthermore, the lateral impact behaviors of hybrid DSTCs, concrete-filled double-skin steel tubes (CFDSTs), and concrete-filled steel tubes (CFSTs) were compared and discussed based on the experimental results in this study as well as in other literature studies. DOI: 10.1061/(ASCE)CC.1943-5614.0001057. (C) 2020 American Society of Civil Engineers.
\end{abstract}

Author keywords: Fiber-reinforced polymer tube; Ultrahigh-performance concrete; Double-skin tubular columns; Lateral impact.

\section{Introduction}

Strengthening of existing reinforced concrete structures using fiber-reinforced polymer (FRP) composites has been widely accepted in the last three decades [ACI 440.2R (ACI 2017); GB 50608 (GB 2012); Lam and Teng 2003; Zeng et al. 2018, 2020a]. The strength, as well as the ductility of existing concrete structures, can be significantly increased by FRP strengthening (Lam and Teng 2003; Teng et al. 2009; Wang et al. 2016, 2017a, 2018a, 2018c). In contrast, to develop new concrete composite members using FRP composites, such as concrete-filled FRP tubes (CFFTs) and hybrid FRP-concrete-steel double-skin tubular columns (DSTCs), is attracting more and more attention (Belzer et al. 2013; Fam and Rizkalla 2001; Mohamed and

\footnotetext{
${ }^{1}$ Research Associate, School of Architecture, Building and Civil Engineering, Loughborough Univ., Loughborough LE11 3TT, UK. Email: W.Wang@lboro.ac.uk; ww674@uowmail.edu.au

${ }^{2}$ Professor, Center for Built Infrastructure Research, School of Civil and Environmental Engineering, Univ. of Technology Sydney, Sydney, NSW 2007, Australia (corresponding author). Email: Chengqing.Wu@uts.edu.au

${ }^{3}$ Professor, Tianjin Key Laboratory of Civil Structure Protection and Reinforcement, Tianjin Chengjian Univ., Tianjin 300384, China. Email: zhongxian1212@163.com

${ }^{4}$ Former Master's Student, Tianjin Key Laboratory of Civil Structure Protection and Reinforcement, Tianjin Chengjian Univ., Tianjin 300384, China. Email: akx8611@126.com

${ }^{5}$ Associate Professor, School of Civil and Transportation Engineering, Guangdong Univ. of Technology, Guangdong 510006, China; Postdoctoral Fellow, Dept. of Civil and Environmental Engineering, Hong Kong Polytechnic Univ., Hong Kong 999077, China. Email: jjzeng@gdut.edu.cn

Note. This manuscript was submitted on September 17, 2019; approved on April 30, 2020; published online on June 26, 2020. Discussion period open until November 26, 2020; separate discussions must be submitted for individual papers. This paper is part of the Journal of Composites for Construction, (C) ASCE, ISSN 1090-0268.
}

Masmoudi 2010; Teng et al. 2007; Wang et al. 2019b; Wong et al. 2008; Yu and Teng 2011; Yu et al. 2010; Zhang et al. 2017).

Hybrid DSTCs are a new form of composite columns that consists of an outer FRP tube and an inner steel tube, with the space between them being filled with concrete (Teng et al. 2007). In the hybrid DSTCs, the fibers in the FRP tube are mainly oriented in the hoop direction. Therefore, the FRP tube can provide confinement onto the concrete and also offer shear resistance of the hybrid DSTCs (Wang et al. 2015). After the novel form of hybrid DSTCs had been proposed, a large amount of investigations were conducted to understand their behaviors under different loading conditions (Idris and Ozbakkaloglu 2016; Ozbakkaloglu and Fanggi 2014; Ozbakkaloglu and Idris 2014; Ozbakkaloglu and Louk Fanggi 2015; Teng et al. 2007; Wang et al. 2015, 2018a; Zeng et al. 2020b, 2015, Zhao et al. 2016). These studies proved that hybrid DSTCs exhibit superior performances under these loading conditions, which makes it a promising column type as compared to other column types. During the service life, the hybrid DSTCs may suffer an accidental lateral impact, such as vehicle/ship collisions. Nevertheless, studies on dynamic responses of DSTCs under lateral impact loading are very limited. The only experimental study on the behavior of hybrid normal-strength concrete (NSC) DSTCs under lateral impact loading, which carried out by Wang et al. (2015), reported that the hybrid NSC DSTCs behaved in a ductile manner and had a long-stabilized stage of impact resistance during the impact. More recently, dynamic performances of bridge piers in the form of hybrid DSTCs against vehicle collision have been numerically investigated, and it was stated that the vehicle impact resistance in DSTCs was primarily carried by the steel tube (Abdelkarim and ElGawady 2016). Although some knowledge has been given, more studies are still needed. Specifically, as an important parameter, the effect of axial load level on the lateral impact behavior of hybrid DSTCs has not been experimentally investigated (Fan et al. 2019; Gholipour et al. 2018; Gurbuz et al. 2019; Thilakarathna et al. 2010). 
In recent years, the use of ultrahigh-performance concrete (UHPC) in the construction industry has been undergoing a rapid growth, which is because of its superior performance over conventional concrete (Magureanu et al. 2012; Shi et al. 2015; Yoo and Banthia 2016). In UHPC, the coarse aggregates are usually replaced by the fine particles, such as silica fume and fly ash (Yoo and Banthia 2016). Moreover, in order to improve the mechanical properties of UHPC (especially the tensile properties), discrete steel/organic fibers can be added into the mix of UHPC (Hannawi et al. 2016; Wu et al. 2016). Due to its unique mixture composition, UHPC usually exhibits ultrahigh strength and toughness, as well as superior durability (Yoo and Banthia 2016). Currently, UHPC has been considered as an ideal construction material to protect concrete structures from extreme impact and blast loads (Othman and Marzouk 2018; Wang et al. 2019a; Wei et al. 2019; Yoo et al. 2015, 2017).

Due to the extraordinary performances of UHPC to resist the extreme dynamic loadings, it is expected that by replacing conventional concrete with UHPC, a higher lateral impact resistance can be achieved for the hybrid DSTCs. Until now, only one study was conducted on the hybrid UHPC DSTCs to investigate their static compressive behavior (Wang et al. 2019b). The results presented in Wang et al. (2019b) demonstrated the superior performance of hybrid UHPC DSTCs over hybrid NSC DSTCs under compressive loading, especially their much higher load-carrying capacity. To the authors' best knowledge, the lateral impact behavior of hybrid UHPC DSTCs has not yet been investigated. For the practical design of hybrid UHPC DSTCs, their dynamic responses under lateral impact loading need to be investigated. Therefore, the current study presents the results of an experimental program on the behavior of hybrid UHPC DSTCs under lateral impact loading. The dynamic responses, including global/local damage modes, lateral deflection-time histories, impact force-time histories, strain-time histories, and acceleration-time histories, were presented and discussed. Moreover, the influences of different parameters on the dynamic responses of hybrid UHPC DSTCs were investigated. Furthermore, the lateral impact behaviors of hybrid DSTCs were compared to those of concrete-filled double-skin steel tube (CFDST) and concrete-filled steel tube (CFST) members to establish their relative performances.

\section{Experimental Program}

\section{Experimental Design}

Seven hybrid DSTCs were manufactured and tested, and the detailed test matrix is provided in Table 1 . All the specimens had a diameter of $168 \mathrm{~mm}$ and a length of 2,000 $\mathrm{mm}$. Except for the hybrid UHPC DSTCs, one hybrid NSC DSTC was also tested for comparison purposes. Other investigated parameters include the axial force level $(0,200 \mathrm{kN})$, impact energy $(7.37 \mathrm{~kJ}, 12.64 \mathrm{~kJ})$, void ratio $(0.57,0.64)$, FRP tube thickness (1 layer, 3 layers),

Table 1. Test matrix

\begin{tabular}{lccccc}
\hline Specimens & $\begin{array}{c}\text { FRP } \\
\text { layers }\end{array}$ & $\begin{array}{c}D_{i} \times t_{i} \\
(\mathrm{~mm})\end{array}$ & $\begin{array}{c}\text { Concrete } \\
\text { type }\end{array}$ & $\begin{array}{c}\text { Axial force } \\
(\mathrm{kN})\end{array}$ & $\begin{array}{c}\text { Impact } \\
\text { height }(\mathrm{m})\end{array}$ \\
\hline DSTC-1 & 3 & $95 \times 4$ & UHPC & - & 1.75 \\
DSTC-2 & 3 & $95 \times 4$ & UHPC & 200 & 1.75 \\
DSTC-3 & 3 & $95 \times 4$ & UHPC & 200 & 3.00 \\
DSTC-4 & 3 & $95 \times 4$ & NSC & 200 & 1.75 \\
DSTC-5 & 3 & $108 \times 4$ & UHPC & 200 & 1.75 \\
DSTC-6 & 1 & $95 \times 4$ & UHPC & 200 & 1.75 \\
DSTC-7 & 0 & $95 \times 4$ & UHPC & 200 & 1.75 \\
\hline
\end{tabular}

and the presence/absence of FRP tubes. Except for Specimen DSTC-5, the inner steel tubes in specimens were identical $\left(D_{o}=\right.$ $95 \mathrm{~mm}, t_{s}=4 \mathrm{~mm}$, in which $D_{o}=$ outer diameter of steel tube and $t_{s}=$ steel tube thickness). While for Specimen DSTC-5, the inner steel tube had a larger size $\left(D_{o}=108 \mathrm{~mm}, t_{s}=4 \mathrm{~mm}\right)$. According to the tensile coupon tests, the average values of the elastic modulus, the yield stress, and the ultimate strength were $200 \mathrm{GPa}, 310$, and $385 \mathrm{MPa}$, respectively, for the $95-\mathrm{mm}$ diameter steel tube. For the 108-mm diameter steel tube, the corresponding average values were $200 \mathrm{GPa}, 343$, and $451 \mathrm{MPa}$, respectively. The cross-sectional configurations of the hybrid DSTCs are shown in Fig. 1.

\section{Specimen Preparation}

Table 2 presents the mix proportion of UHPC used in this study. It is noted that straight steel fibers were added into the mix, and the details of mechanical properties of steel fibers are presented in Table 3. Detailed instructions on the mixing process of UHPC were given in Wang et al. (2019b). In contrast, the mix proportion of NSC was readily available from the market, and its maximum aggregate size was $10 \mathrm{~mm}$. The cylindrical compressive strengths of the UHPC and the NSC were determined by compression

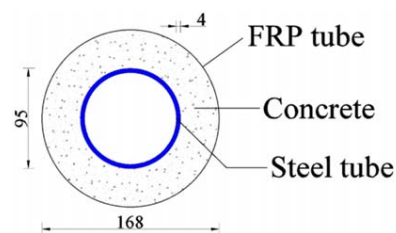

(a)

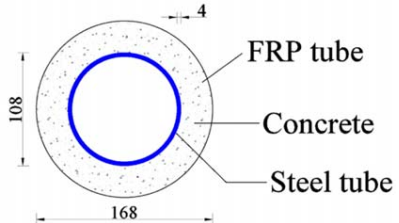

(b)

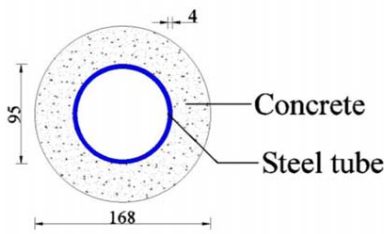

(c)

Fig. 1. Cross sections of specimens (all units in mm): (a) DSTC-1, 2, 3, 4, 6; (b) DSTC-5; and (c) DSTC-7

Table 2. Mix proportion of UHPC per $\mathrm{m}^{3}$ (unit in $\mathrm{kg}$ )

\begin{tabular}{lc}
\hline Elements & Amounts \\
\hline 52.5 cement & 750 \\
Silica fume & 225 \\
Quartz flour & 190 \\
Fine sand & 1,030 \\
Superplasticizer & 16 \\
Water & 190 \\
Nano particles & 21.7 \\
Steel fiber & 191 \\
\hline
\end{tabular}

Table 3. Mechanical properties of steel fibers

\begin{tabular}{lc}
\hline Properties & Values \\
\hline Elastic modulus $(\mathrm{GPa})$ & 210 \\
Tensile strength $(\mathrm{MPa})$ & 4,295 \\
Diameter $(\mathrm{mm})$ & 0.12 \\
Length $(\mathrm{mm})$ & 15 \\
Aspect ratio & 125 \\
\hline
\end{tabular}


tests. Three 150-mm diameter concrete cylinders with a length-todiameter ratio of 2 were tested under axial compression by following the AS 1012.9 (AS 2014). The average compressive strengths for the UHPC and NSC were 136 and $35 \mathrm{MPa}$, respectively.

The hybrid DSTCs were prepared as follows. First, polyvinyl chloride (PVC) tubes with a 168-mm inner diameter and a 2,000-mm height were prepared. Second, the inner steel tubes were precisely cut into segments with a 2,000-mm length and were then installed into the PVC tubes. It is noted that both tubes were concentrically placed before pouring concrete. Third, both tubes were placed vertically, and then, the concrete was poured in between these two tubes. Since there were no coarse aggregates, the UHPC had a high workability, which made it very suitable for casting. A vibrator was also used to ensure the casting quality of UHPC. Moreover, due to the existence of coarse aggregates $(10 \mathrm{~mm})$ and the relatively small dimensions of the hybrid DSTCs, the vibrator was continuously used when the NSC was cast. Fourth, the prepared hybrid DSTCs were cured in room temperature for 1 day, and then, they were placed into the $90^{\circ} \mathrm{C}$ hot water for another 2 days. Afterwards, the hybrid DSTCs were taken out from the hot water, and the PVC pipe was removed after 7 days of concrete casting. It was noted that the concrete surface should not be damaged during the removal of PVC pipes. Finally, the hybrid DSTCs were manually wrapped with FRP following the wet lay-up procedure, in which all the fibers were wrapped in the hoop direction. A 100-mm overlap was ensured for the hybrid DSTCs to prevent the premature debonding of FRP. After these procedures, all the hybrid DSTCs were placed in room temperature again until the date of testing.

The carbon FRP (CFRP) sheet was supplied by Nanjing Hitech Composites Co. (2015). The original width of the CFRP sheet was $300 \mathrm{~mm}$, and the nominal thickness was $0.167 \mathrm{~mm}$ per layer. Based on the manufacturer's data, the CFRP sheet had an ultimate tensile strength of $3,400 \mathrm{MPa}$ and an ultimate tensile strain of 0.017 . The properties of the CFRP sheet were also determined by coupon tests as per ASTM D7565/D7565M (ASTM 2010). Five coupons were tested, and these coupons had designed dimensions of $25 \times$ $250 \mathrm{~mm}$. The detailed tensile test results of FRP flat coupons are provided in Table 4.

\section{Test Setup}

A drop hammer system was used to carry out the lateral impact tests in this study, as presented in Fig. 2. The drop hammer, which has a weight of $430 \mathrm{~kg}$, is composed of a frame and an impactor. A clamping system with a length of $250 \mathrm{~mm}$ was specially designed to realize the fully clamped boundary conditions. The clamping system included a top steel component and a bottom steel component, and the hybrid DSTC was placed in between these two components and then fixed by them. After the hybrid DSTC was properly placed, six 32-mm diameter high-strength steel bolts and four 24-mm diameter high-strength steel bolts were used to fix the clamping system. The two steel components were connected to the steel supporting system, and this steel supporting system was connected to the rigid supporting platform.

Table 4. Tensile test results of FRP flat coupons (3 layers)

\begin{tabular}{lc}
\hline Properties & Values \\
\hline Width $(\mathrm{mm})$ & 28.50 \\
Nominal thickness $(\mathrm{mm})$ & 1.05 \\
Average elastic modulus $(\mathrm{GPa})$ & 144 \\
Average tensile strength $(\mathrm{MPa})$ & 2,471 \\
Average ultimate strain $(\mathrm{mm} / \mathrm{mm})$ & 0.0172 \\
\hline
\end{tabular}

A wedge-shaped impactor was used, which was $25 \mathrm{~mm}$ in radius at the impactor end, as shown in Figs. 3(a) and 4. A bladder accumulator, which was connected to a hydraulic oil pump and a hydraulic jack, was used to apply the axial load (Zhi et al. 2018), as shown in Fig. 3(b). A reaction steel plate was used to balance the axial load, as shown in Fig. 3(c). More details on the load application system were given by Zhi et al. (2018). Three linear variable differential transformers (LVDTs) were installed at the bottoms of the midspan, one-third span, and one-sixth span to record the lateral deflections, as shown in Figs. 3(d) and 4. The data acquisition frequency of LVDTs and load cell was $100 \mathrm{kHz}$.

To better understand the deformation mechanism of hybrid DSTCs during the test, strain gauges were used to record the deformations of different locations. Thirteen strain gauges were used for each specimen. Fig. 4 shows the specific arrangements of strain gauges. Specifically, Strain gauges S-2, S-3, S-5, S-7, S-10, and S-12 were arranged in the hoop direction, while the other strain gauges were arranged in the longitudinal direction. The clear span of the hybrid DSTC was $1,400 \mathrm{~mm}$. A force transducer was employed to record the impact force-time history, with the former being placed between the impactor and the drop hammer.

\section{Experimental Results}

\section{Damage Modes}

The global damage modes of the hybrid DSTCs are shown in Fig. 5. Residual deflections can be clearly observed for all the specimens. Except for Specimen DSTC-7 without the FRP tube, the lateral deflections were mainly flexural deflections. As can be observed from Figs. 5( $\mathrm{a}$ and b), with the applied axial load, the residual deflection became smaller. Moreover, by increasing the impact energy from 7.37 to $12.64 \mathrm{~kJ}$, the residual deflection was significantly increased [Figs. 5(b and c)]. Several studies indicated the change of failure mode from flexural to shear failure when the impact energy is higher (Fan et al. 2019; Gurbuz et al. 2019). While in

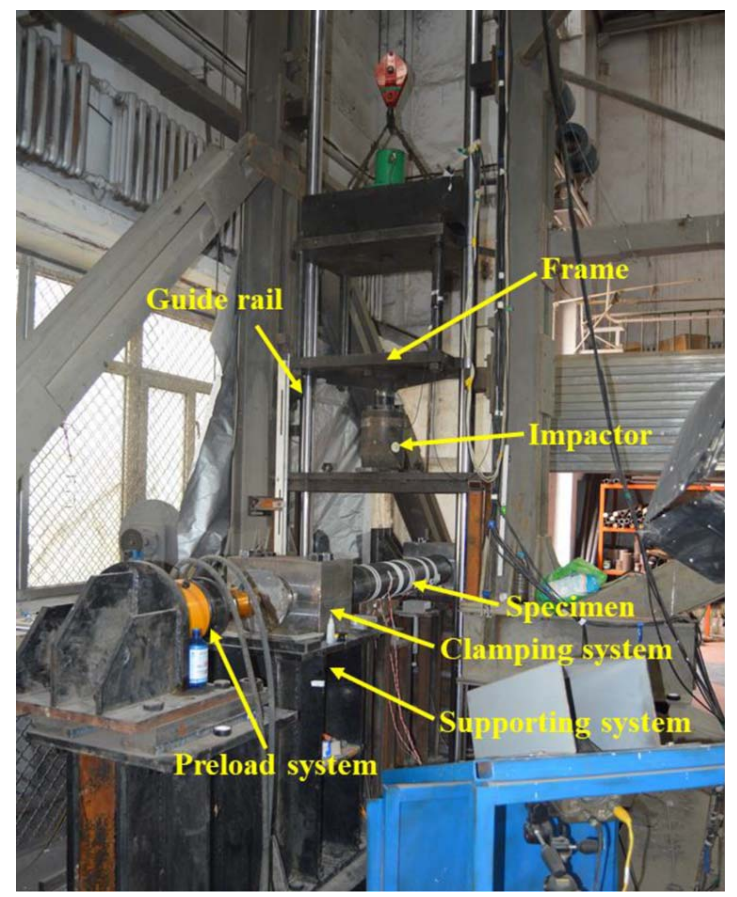

Fig. 2. Impact test setup. 


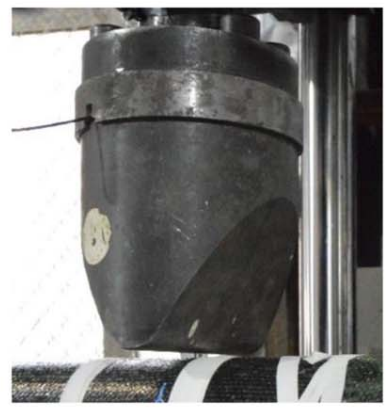

(a)

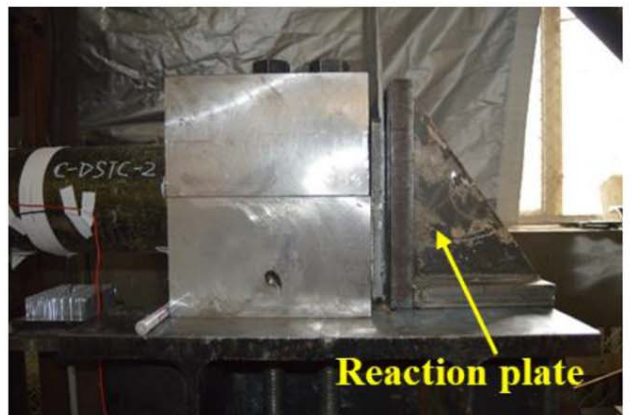

(c)

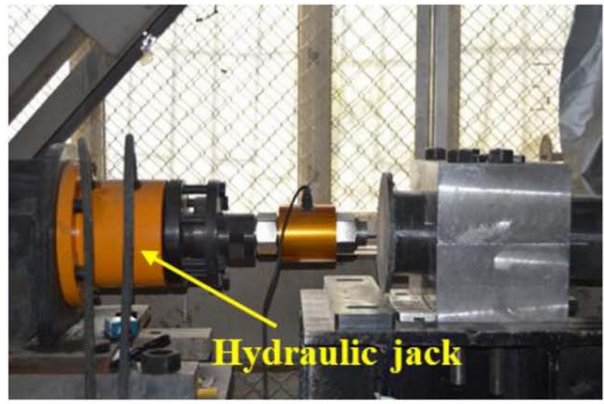

(b)

Fig. 3. Details of impact test: (a) wedge-shaped impactor; (b) preload application; (c) reaction plate; and (d) LVDTs and strain gauges installation.

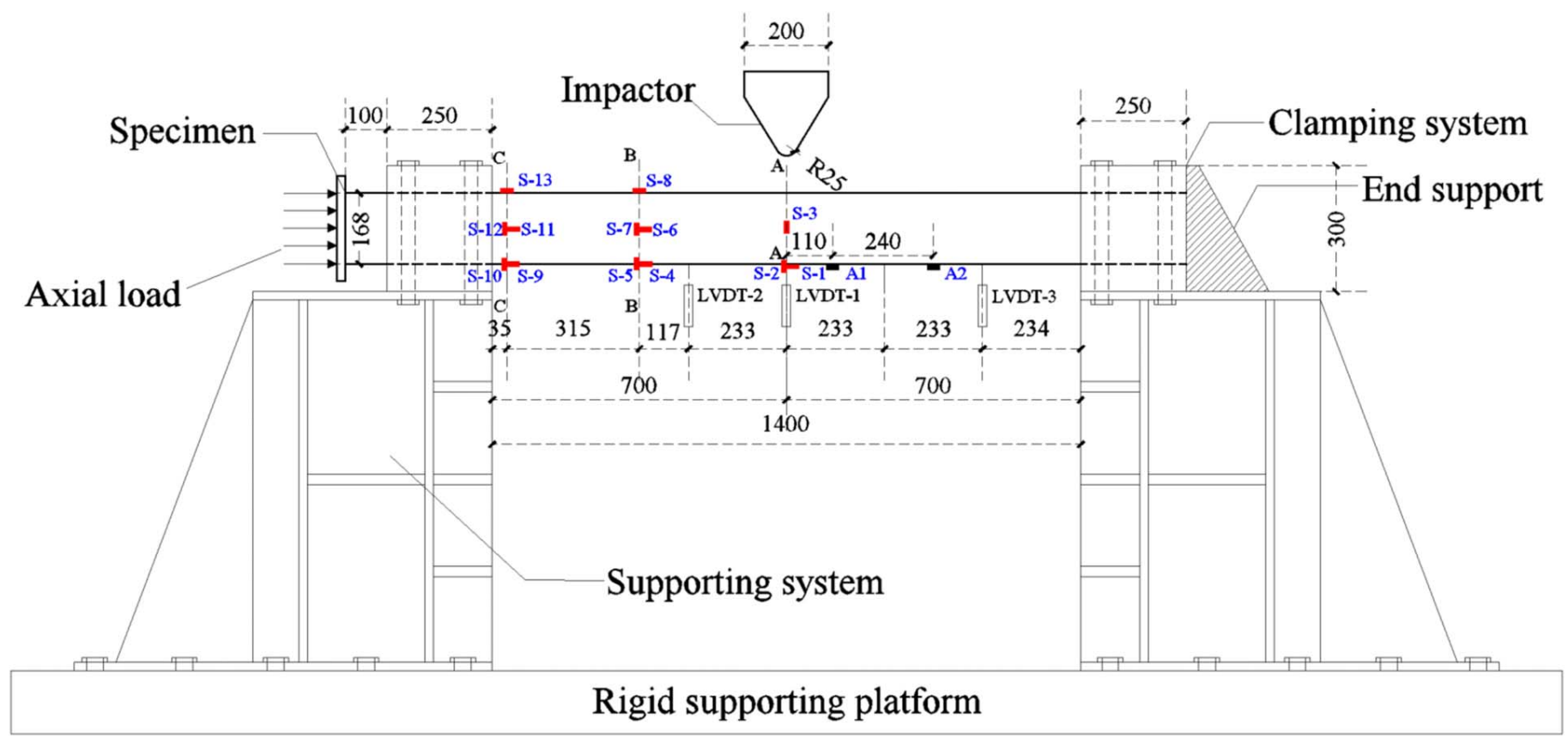

Fig. 4. Details of specimens (all units in $\mathrm{mm}$ ).

this study, the specimens all exhibited flexural failure, and no shear failure was observed. There are two reasons for such behavior. First, compared to the traditional reinforced concrete members with reinforcement ratios usually less than $2 \%$, the reinforcement ratios of hybrid DSTCs in this study were much higher (above $5 \%$ ), and thus, it was unlikely to exhibit shear failure with such a higher reinforcement ratio. Second, in addition to the inner steel tube that could provide shear resistance, the outer CFPR tube could also provide significant shear resistance since all the carbon fibers were oriented in the hoop direction, which acted as a continuous CFRP stirrup (Wang et al. 2018b).

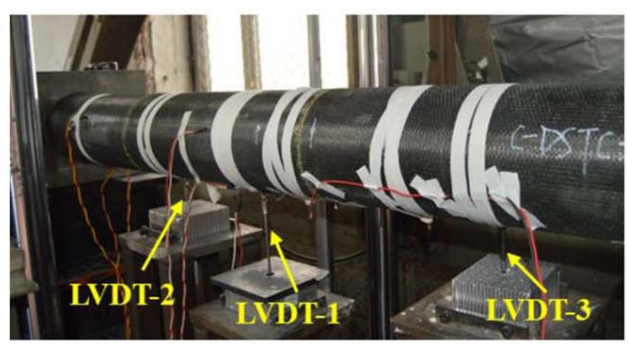

(d)
Based on the comparisons between Figs. 5(b and d), it is evident that by replacing NSC with UHPC, the lateral residual deflection can be significantly decreased. On the other hand, by comparing the lateral residual deflections of Specimens DSTC-2 and DSTC-5, it was concluded that a higher void ratio resulted in a lower residual deflection. In addition, the FRP tube thickness could also affect the lateral residual deflection of hybrid DSTC: the thicker FRP tube resulted in a smaller lateral residual deflection [Figs. 5(b and f)]. For Specimen DSTC-7 without the FRP tube, significant larger lateral residual deflection than other specimens with FRP tubes was observed, and the lateral

\section{.}


deflection was a combination of flexural and shear deflections

[Fig. 5(g)].

The localized damage patterns of the hybrid DSTCs were also investigated, as shown in Fig. 6. Fiber breakage and epoxy damage

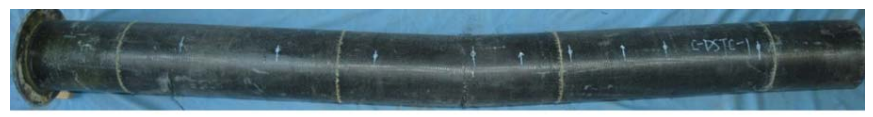

(a)

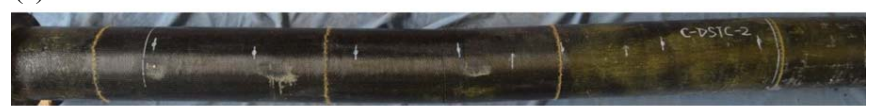

(b)

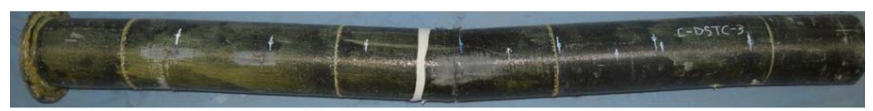

(c)

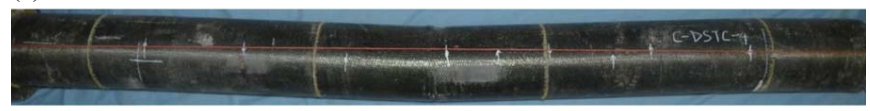

(d)

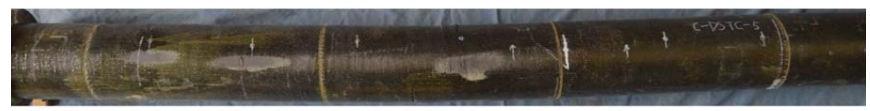

(e)

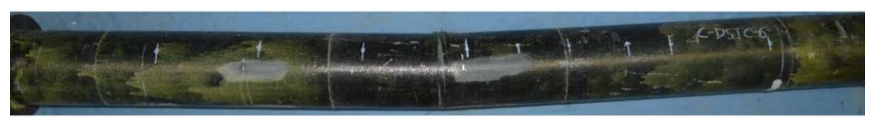

(f)

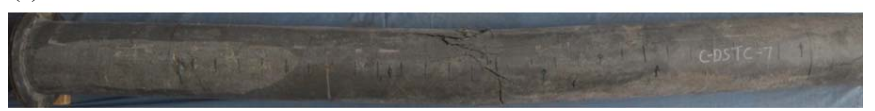

(g)

Fig. 5. Global damage modes: (a) DSTC-1; (b) DSTC-2; (c) DSTC-3; (d) DSTC-4; (e) DSTC-5; (f) DSTC-6; and (g) DSTC-7.

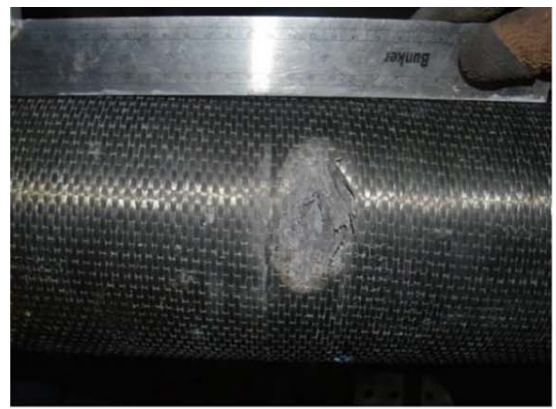

(a)

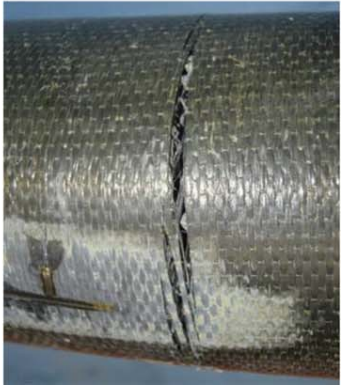

(c) in the impact region were observed, as shown in Fig. 6(a). For the specimen with a one layer-FRP tube (DSTC-6), fiber breakage and epoxy damage became more severe, and debonding of the FRP tube was also observed [Fig. 6(b)]. In addition, concrete cracks were observed at the midspan bottom for all the specimens. For the hybrid UHPC DSTCs, the pullout of steel fibers could be clearly observed, as shown in Fig. 6(b). This mechanism between the steel fibers and the concrete matrix could effectively prevent the further development of cracks for UHPC (Hannawi et al. 2016; Yoo et al. 2015). While for the hybrid NSC DSTC, the cracking was more severe than the hybrid UHPC DSTCs, and coarse aggregates could be observed [Fig. 6(c)]. In addition, concrete cracks were also observed at the top specimen end, but less severe [Fig. 6(d)]. For Specimen DSTC-7, the localized concrete damage in the impact region was very severe, and significant concrete cracking and crushing occurred, which was mainly due to the absence of the FRP tube [Figs. 7(a and b)]. Cross-shaped cracks were observed at the midspan bottom [Fig. 7(c)]. Moreover, shear cracks were observed at the midspan as well as at the specimen end, as shown in Figs. 7(a and d). It is also noted that the impactor shape may affect the global/local response, especially the localized damage patterns of the hybrid DSTCs. Therefore, it would be interesting to investigate this influence in further study.

\section{Deflection-Time Histories}

Table 5 presents the detailed test results of this study, including the impact velocity $v$, the maximum midspan deflection $\Delta_{1}$, the residual midspan deflection $\Delta_{2}$, the peak impact force $F_{p}$, the plateau impact force $F_{s}$, and the impact duration $t_{o}$. The plateau impact force is defined by (Wang et al. 2017b, 2019a)

$$
F_{s}=\int_{t_{1}}^{t_{2}} F(t) d t / T
$$

where $t_{1}$ and $t_{2}=$ time at the beginning and the end of the plateau impact stage, respectively; $F(t)=$ impact force at the time of $t$; and

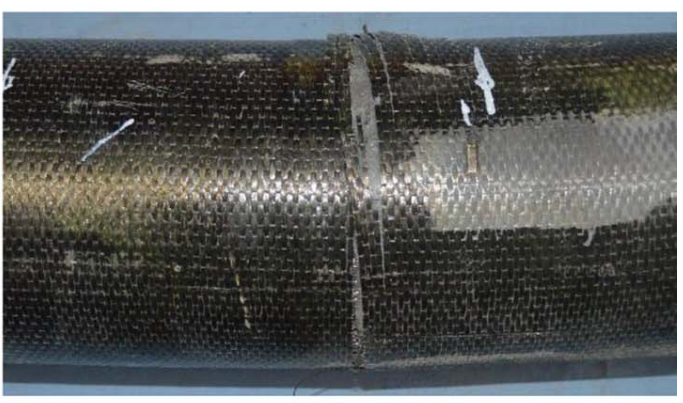

(b)

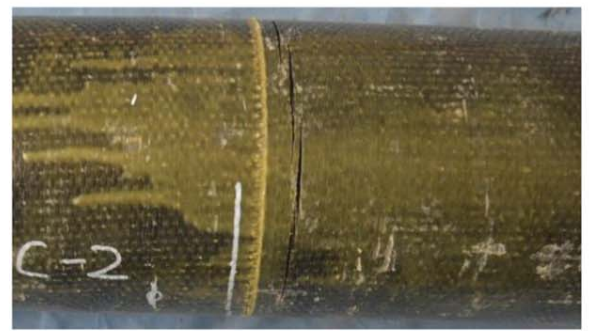

(d)

Fig. 6. Localized damage patterns: (a) fiber breakage and epoxy damage in the impact region; (b) FRP debonding in the impact region and cracks of UHPC at the midspan bottom; (c) cracks of NSC at the midspan bottom; and (d) concrete cracking at the top specimen end. 


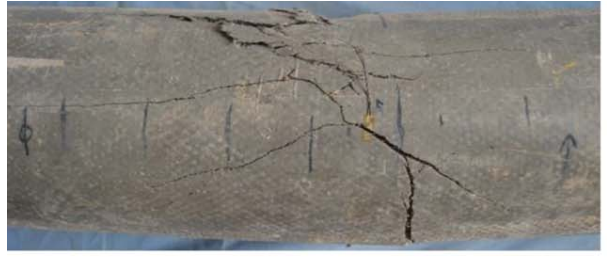

(a)

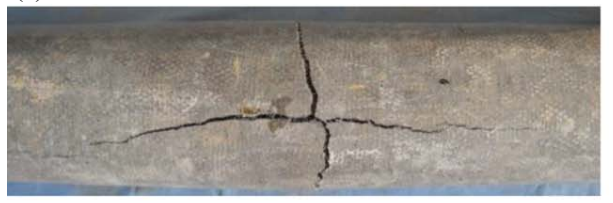

(c)

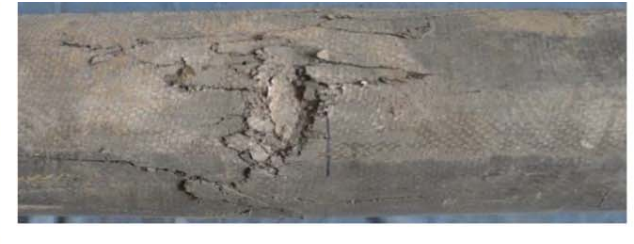

(b)

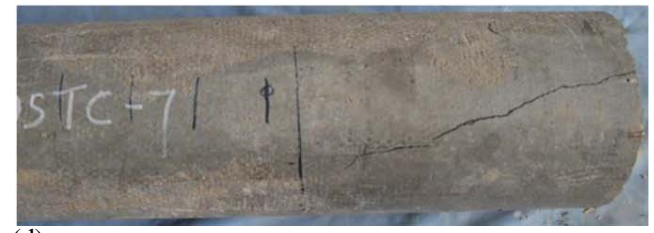

(d)

Fig. 7. Localized damage patterns for Specimen DSTC-7: (a) localized damage in the midspan; (b) concrete crushing in the impact region; (c) concrete cracking at the midspan bottom; and (d) shear cracks at the specimen end.

Table 5. Summary of test results

\begin{tabular}{|c|c|c|c|c|c|c|c|c|c|c|c|}
\hline Specimen & $v(\mathrm{~m} / \mathrm{s})$ & $\Delta_{1}(\mathrm{~mm})$ & $\Delta_{2}(\mathrm{~mm})$ & $\Delta_{2} / \Delta_{1}$ & $F_{p}(\mathrm{kN})$ & $F_{s}(\mathrm{kN})$ & $t_{o}(\mathrm{~ms})$ & $W_{1}(\mathrm{~kJ})$ & $W_{2}(\mathrm{~kJ})$ & $W_{3}(\mathrm{~kJ})$ & $W_{1} / W_{2}$ \\
\hline DSTC-1 & 5.86 & 30.8 & 17.7 & 0.57 & 220 & 154 & 19.6 & 3.83 & 7.37 & 4.00 & 0.52 \\
\hline DSTC-2 & 5.86 & 29.1 & 15.3 & 0.53 & 228 & 173 & 18.1 & 3.76 & 7.37 & 4.09 & 0.51 \\
\hline DSTC-3 & 7.67 & 43.9 & 29.8 & 0.68 & 282 & 169 & 22.7 & 6.85 & 12.64 & 7.14 & 0.54 \\
\hline DSTC-4 & 5.86 & 37.5 & 24.6 & 0.66 & 167 & 133 & 21.8 & 4.01 & 7.37 & 4.19 & 0.54 \\
\hline DSTC-5 & 5.86 & 25.2 & 12.4 & 0.49 & 203 & 181 & 18.6 & 2.99 & 7.37 & 3.33 & 0.41 \\
\hline DSTC-6 & 5.86 & 33.7 & 18.6 & 0.55 & 230 & 159 & 20.2 & 3.62 & 7.37 & 3.84 & 0.49 \\
\hline DSTC-7 & 5.86 & 37.3 & 24.2 & 0.65 & 223 & 118 & 24.0 & 3.57 & 7.37 & 3.74 & 0.48 \\
\hline
\end{tabular}

$T=$ plateau impact stage duration. The definition of the plateau impact stage was discussed in Wang et al. (2017b), where $t_{1}=$ first trough after the peak impact force and $t_{2}=$ beginning of the descending branch.

The deflection-time $(\Delta-t)$ histories of tested hybrid DSTCs are shown in Fig. 8. The deflections at different locations have a similar trend, that is, they increase to the maximum deflection first and then decrease until the residual deflection is reached. Afterwards, the hybrid DSTCs vibrate freely around the residual deflection until the final stop of specimens. The midspan $\Delta-t$ histories of the hybrid DSTCs are shown together in Fig. 9. Specimen DSTC-2 exhibits lower maximum and residual midspan deflections than Specimen DSTC-1. Therefore, the preloaded $200-\mathrm{kN}$ axial force is beneficial to increase the lateral impact resistance of the hybrid DSTCs. Similar observations have been reported from other studies on concrete-filled steel tube columns and reinforced concrete columns (Fan et al. 2019; Hou et al. 2019; Wei et al. 2019). However, it should be noted that the current observation is based on a low-level axial force. If this axial force was greater, this observation might not be true since the second-order effect cannot be neglected (Hou et al. 2019).

In addition, with the increase of impact energy (DSTC-2 and DSTC-3), the maximum deflection increases significantly from 29.1 to $43.9 \mathrm{~mm}$, and the residual deflection increases from 15.3 to $29.8 \mathrm{~mm}$, respectively. Also, after comparing the test results of Specimens DSTC-2 and DSTC-4, it is evident that the hybrid UHPC DSTCs exhibit significantly lower deflections than the hybrid NSC DSTCs. Furthermore, the ratio between the residual midspan deflection to the maximum midspan deflection $\left(\Delta_{2} / \Delta_{1}\right)$ is calculated and presented in Table 5. A ratio of 0.53 is observed for Specimen DSTC-2, while a ratio of 0.66 is observed for Specimen DSTC-4. Therefore, the UHPC can more effectively decrease the residual deflection of the hybrid DSTCs than NSC, as in line with findings reported by Wang et al. (2019a). This phenomenon is mainly due to the extraordinary tensile behavior of UHPC, especially its postcrack strain hardening behavior (Tran et al. 2015; Wille et al. 2014). After the tensile cracks occur, the tensile stress of UHPC can be still very high with a much higher tensile strain capacity than NSC. Therefore, the UHPC can provide considerable tensile resistance after the initial development of tensile cracks, and therefore, the residual deflection of the hybrid DSTCs can be more effectively reduced. Moreover, the $\Delta_{2} / \Delta_{1}$ ratio increases from 0.53 to 0.68 with a higher impact energy (12.64 kJ for DSTC-3), which indicates that the proportion of the recoverable deflection becomes less with a higher impact energy.

Among all specimens, Specimen DSTC-5 with a higher void ratio $(0.64)$ achieves the lowest midspan deflections. Due to the increase of the void ratio, the impact resistance from the infilled UHPC reduces, while the steel tube's impact resistance capacity increases and can even result in a larger global impact resistance capacity of the hybrid DSTCs. For Specimen DSTC-6 with a 1-layer-FRP tube, its maximum and residual midspan deflections are significantly higher than those of Specimen DSTC-2 with a 3-layer-FRP tube. Similarly, for Specimen DSTC-7 without the FRP tube, the maximum and residual midspan deflections further increase as compared to those of Specimens DSTC-2 and DSTC-6. As is evident from the damage modes shown in Figs. 5 and 7, the presence of the FRP tube can effectively prevent the development of shear cracks and thus improve the overall lateral impact resistance capacity of the hybrid DSTCs. Moreover, by increasing the FRP layers, the ratio between the residual midspan deflection and the maximum midspan deflection is $0.65,0.55$, and 0.53 , respectively, for Specimens DSTC-7, DSTC-6, and DSTC-2. Therefore, more lateral deflection can be recovered by increasing the FRP layers. 

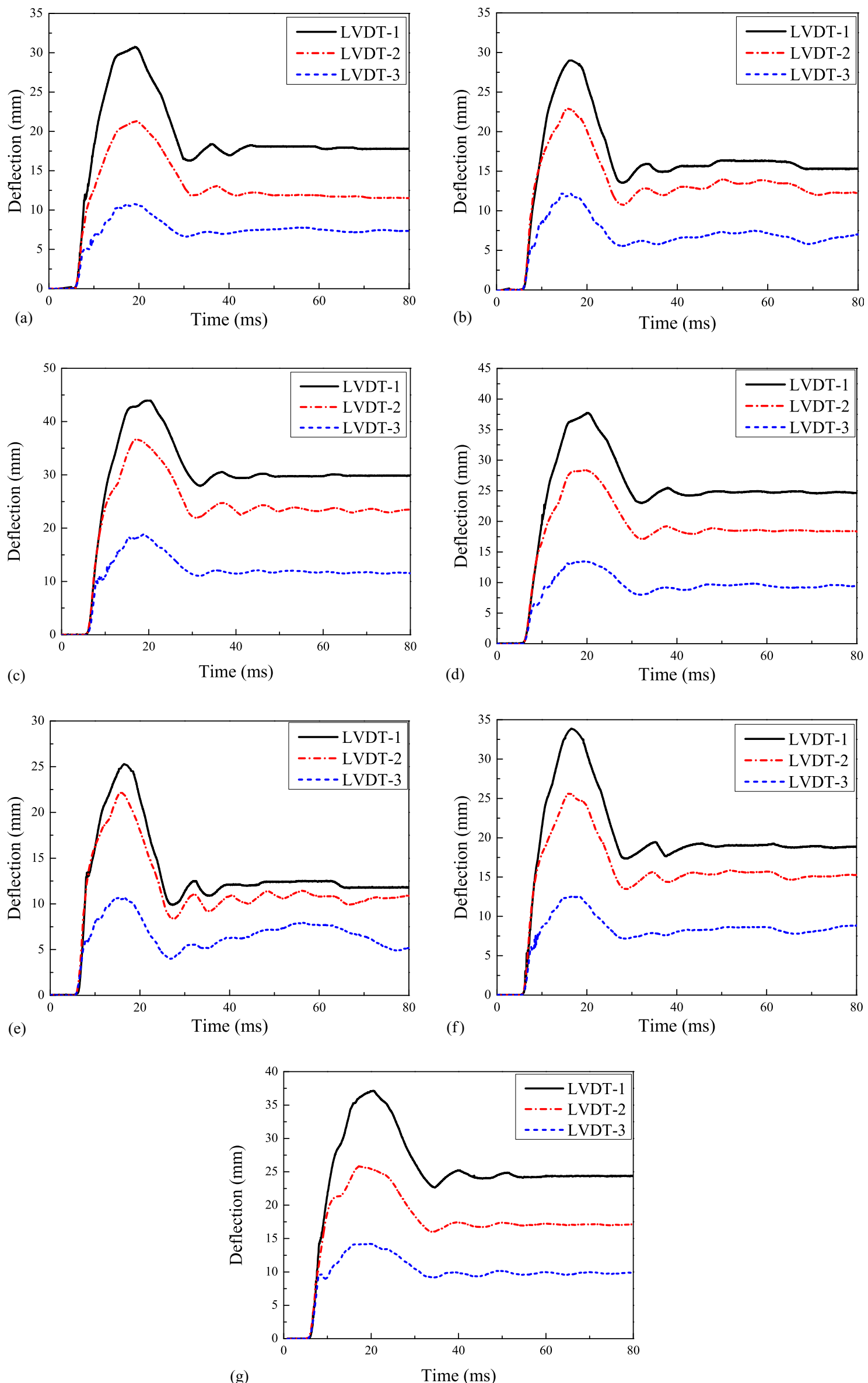

Fig. 8. Deflection-time ( $\Delta-t$ ) histories: (a) DSTC-1; (b) DSTC-2; (c) DSTC-3; (d) DSTC-4; (e) DSTC-5; (f) DSTC-6; and (g) DSTC-7. 


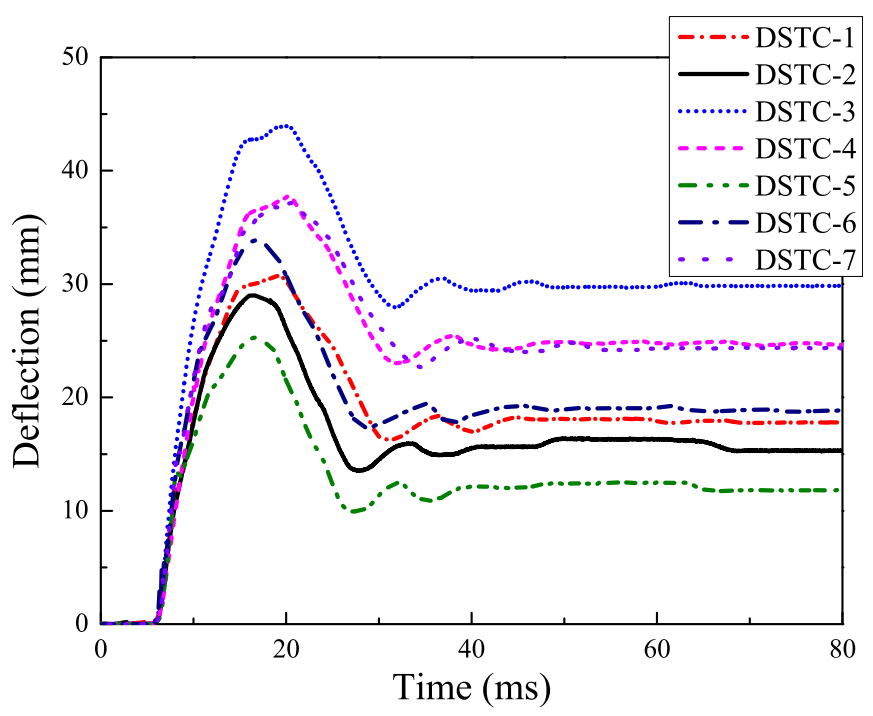

Fig. 9. Midspan deflection-time $(\Delta-t)$ histories.

\section{Impact Force-Time Histories}

The impact force-time $(F-t)$ histories of the tested hybrid DSTCs are shown in Fig. 10. The $F-t$ histories were presented in different figures for better comparisons. Generally, the impact process has three different stages. In Stage 1, an instant increase of impact force to the peak force is observed. In this stage, the lateral deflection of hybrid DSTCs is very small due to the very short duration of this stage. In Stage 2, the impact force varies around the plateau impact force, which reflects the specimen's real lateral impact resistance capacity. In Stage 3, the impact force continuously decreases until it becomes zero, which indicates that the impactor was separated from the hybrid DSTCs.

The effects of different variables on the $F-t$ histories of hybrid DSTCs are investigated (Table 5 and Fig. 10). Specifically, with a $200-\mathrm{kN}$ axial load, the peak/plateau impact force slightly increases, and the impact duration decreases [Fig. 10(a)]. By increasing the impact energy from 7.37 to $12.64 \mathrm{~kJ}$, the peak impact force becomes larger, and the impact duration becomes longer. Nevertheless, the change of plateau impact force is insignificant [Fig. 10(b)]. The hybrid UHPC DSTCs exhibit significantly larger peak/plateau impact force and less duration than the hybrid NSC DSTCs, as shown in Fig. $10(\mathrm{c})$. Increasing the void ratio from 0.57 to 0.64 results in the decrease of the peak impact force as well as a slight increase of the plateau impact force [Fig. 10(d)]. The influence of CFRP layers on the peak/plateau force is moderate, while the impact duration decreases with increasing the CFRP layers [Fig. 10(e)]. The lateral impact behavior of hybrid DSTCs is greatly improved with the existence of an FRP tube [Fig. 10(f)].

The lateral impact performance of hybrid DSTCs should be evaluated in two main aspects: the deflection-time history and the impact force-time history. As is observed from Fig. 10, for the specimens with different void ratios (DSTC-2 and DSTC-5), the differences between the plateau impact forces are slight. The plateau impact force can reflect the specimen's global lateral impact resistance capacity. Therefore, it is considered that the global lateral impact resistance capacities are similar for these two specimens. On the other hand, despite the similar lateral impact resistance capacities, the lateral deflection is smaller for Specimen DSTC-5 with a larger void ratio, as shown in Fig. 9. Due to the larger void ratio, the local stiffness in the impact region is smaller, which can be demonstrated by the peak impact forces $(203 \mathrm{kN}$ for DSTC-2 and $228 \mathrm{kN}$ for DSTC-5). Therefore, a higher proportion of impact energy is dissipated in the impact region to generate the localized deformation for Specimen DSTC-5, and thus, the energy to generate the overall deflection becomes smaller, and the global lateral deflection is lower accordingly.

\section{Impact Force-Midspan Deflection Histories}

The impact force-midspan deflection $(F-\Delta)$ histories of the hybrid DSTCs are provided in Fig. 11. When the peak impact force is reached, the midspan deflection is rather small. Following this, the impact force exhibits a significant decrease, and the midspan deflection has a moderate increase. Afterwards, the midspan deflection has a rapid increase until the peak deflection reaches the plateau impact stage's end. The hybrid DSTCs then started to move upwards by continuously releasing the stored energy. Accordingly, both the impact force and the deflection decreased until the impact force became zero when the impactor separated from the hybrid DSTC.

During the impact, the impact energy was finally dissipated to zero because of the combined effects of friction, sound, and damping. Therefore, it is interesting to investigate how much the impact energy was absorbed by the specimen to generate the lateral deflection. In this section, the work done to the specimen $\left(W_{1}\right)$ equals the production of impact force and midspan deflection. That is, $W_{1}$ was calculated as the area of the impact force-midspan deflection curve. The work done to the specimen $\left(W_{1}\right)$, the impact energy $\left(W_{2}\right)$, and the ratio $\left(W_{1} / W_{2}\right)$ is presented in Table 5. In addition, the work done to the specimen during the whole impact process (multiple impacts until the impact hammer finally stopped) is also calculated $\left(W_{3}\right)$, as shown in Table 5 . As can be seen in Table 5, except for Specimen DSTC-5 with a large void ratio, the $W_{1} / W_{2}$ ratio is about 0.5 . This indicates that almost half of the impact energy is dissipated because of other factors rather than deforming the specimens. For Specimen DSTC-5, the lower $W_{1} / W_{2}$ ratio $(0.41)$ is at least partially due to the increased local indentation in the impact region: by using the global lateral deflection, the local indentation cannot be considered, which will result in a lower $W_{1} / W_{2}$ ratio. Moreover, by comparing the values of $W_{1}$ and $W_{3}$, the first impact dissipates most of the work done to the hybrid DSTCs during the whole impact.

\section{Strain-Time Histories}

Fig. 12 shows the strain-time histories of the hybrid DSTCs, in which positive readings indicate tension and vice versa. The specific strain gauges' locations are provided in Fig. 4. Some strain gauges were damaged and thus the data from them were not recorded. From Fig. 12, the largest longitudinal tensile strain usually occurs at the midspan bottom (S-1) for several specimens. The readings of several strain gauges in the midspan region suddenly increase from zero to a very large value that exceeds the limits of the strain gauges [Figs. 12(a, e, f, and g)]. For these specimens, concrete cracking occurred at the locations where these strain gauges were installed. For Specimen DSTC-7, the hoop strain gauge $(\mathrm{S}-3)$ in the midspan region was broken shortly after the impact, which was due to the occurrence of inclined shear cracks in this region [Fig. 7(a)].

Moreover, considerable residual strains are observed after the impact, especially in the midspan region (A-A section) as well as the end region ( $\mathrm{C}-\mathrm{C}$ section). Moreover, the strain values at the B-B section are significantly smaller than those at the A-A section, which is because the smaller deformations at the B-B section. The strain values at the C-C section are larger than those at the B-B section for several specimens possibly because of the boundary constraints. Within the specimen's end region, longitudinal tension occurs at the top of the specimen end (S-13), while longitudinal compression occurs at the bottom of the specimen end (S-9). 

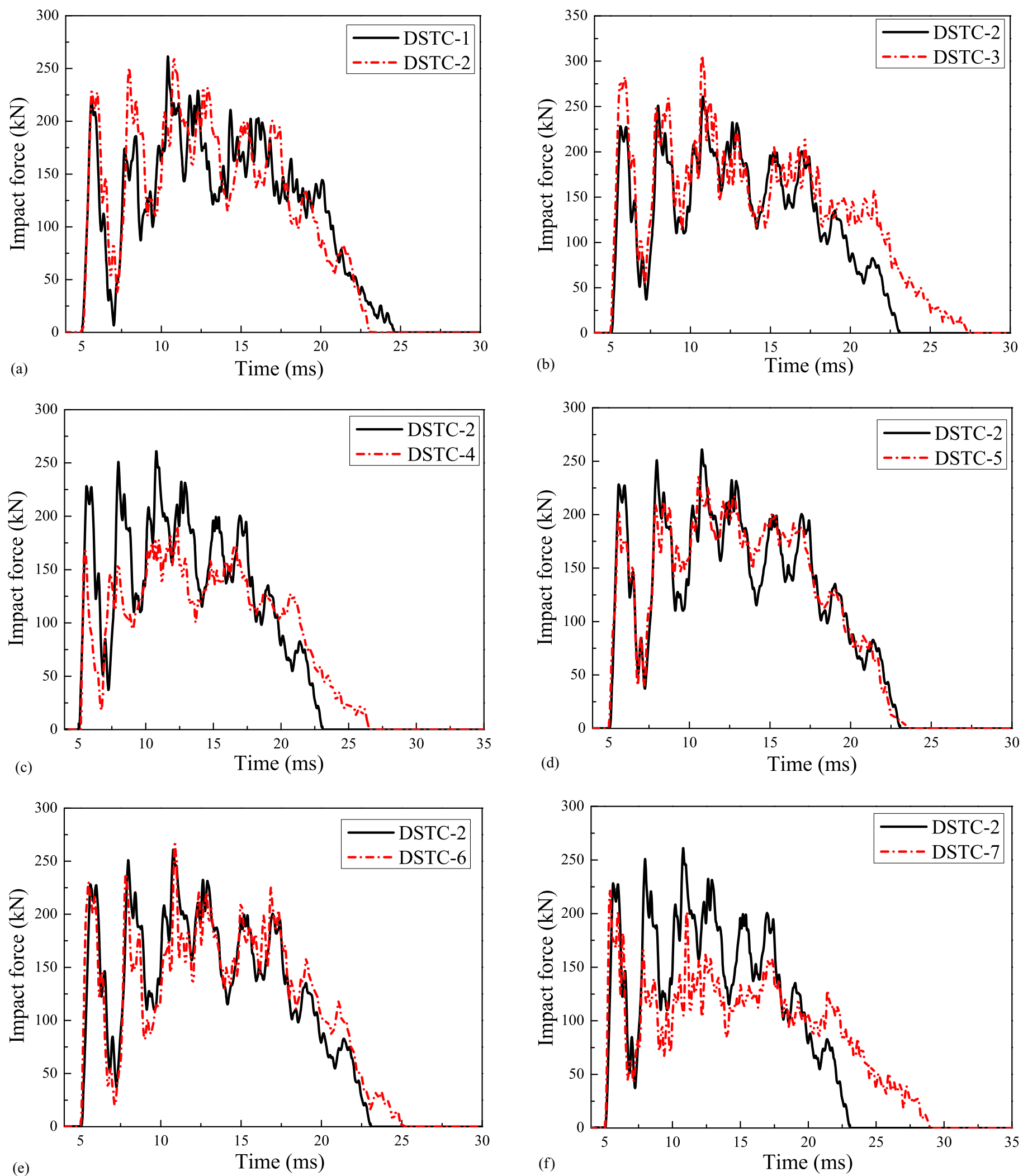

Fig. 10. Impact force-time histories: (a) axial load level; (b) impact energy; (c) concrete type; (d) void ratio; (e) FRP tube thickness; and (f) presence/ absence of the FRP tube.

\section{Acceleration-Time Histories}

Two accelerometers were attached at the bottom of the specimen, as shown in Fig. 4. One accelerometer (A1) was installed in the midspan region (110 $\mathrm{mm}$ right of the midspan bottom), and the other accelerometer (A2) was installed in the one-quarter span region ( $350 \mathrm{~mm}$ right of the midspan bottom). The clear distance between these two accelerometers was $240 \mathrm{~mm}$. The acceleration-time histories were recorded, as shown in Fig. 13. These curves exhibit very large fluctuations during the impact. The vertical acceleration at 

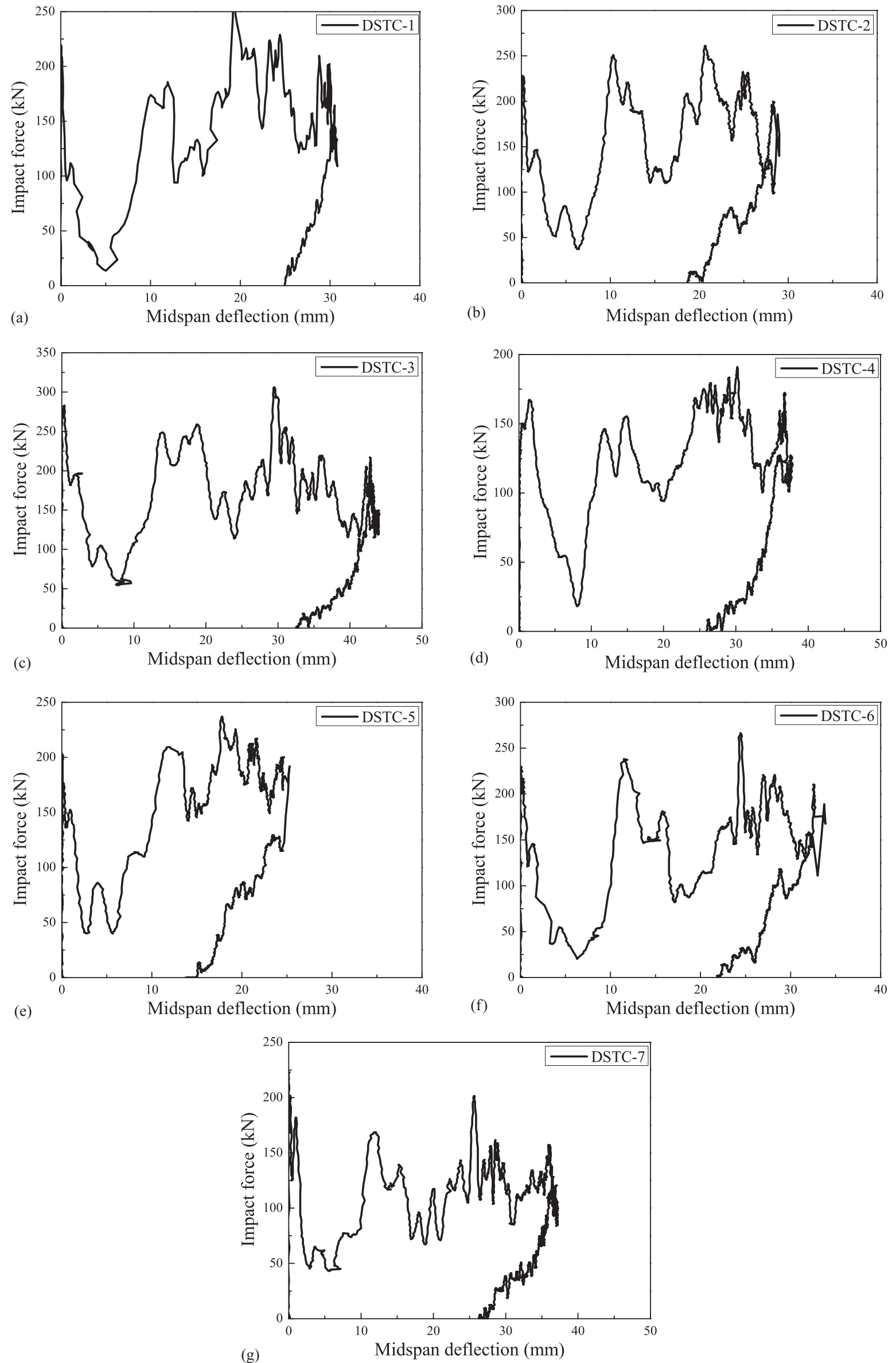

Fig. 11. Impact force-midspan deflection histories: (a) DSTC-1; (b) DSTC-2; (c) DSTC-3; (d) DSTC-4; (e) DSTC-5; (f) DSTC-6; and (g) DSTC-7. 

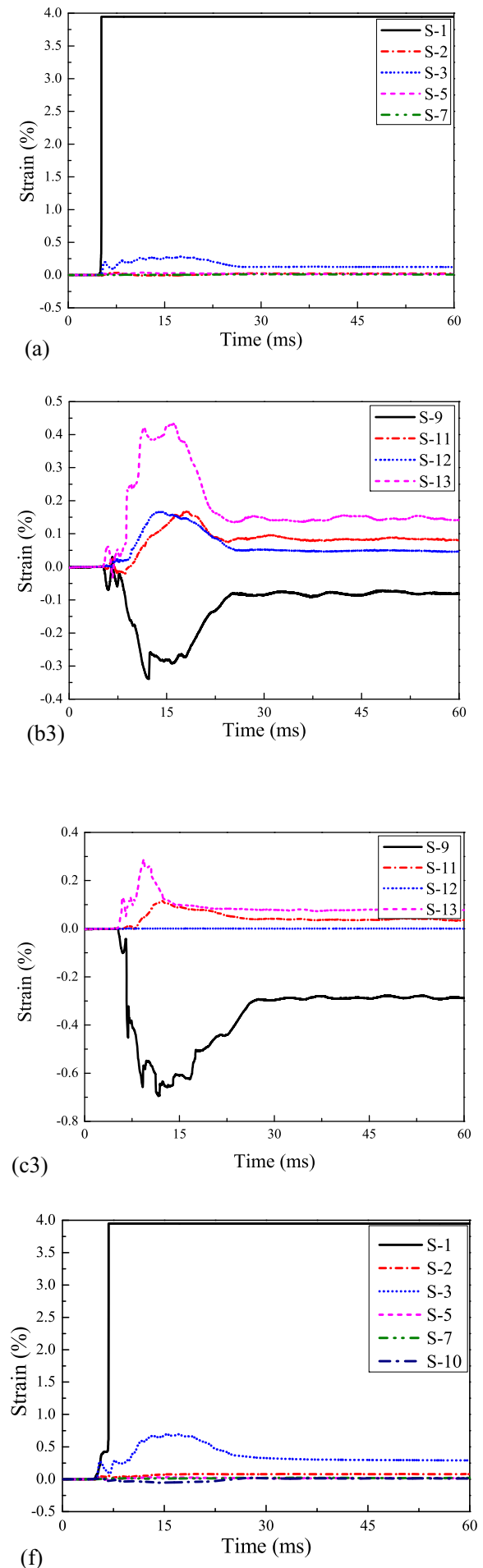
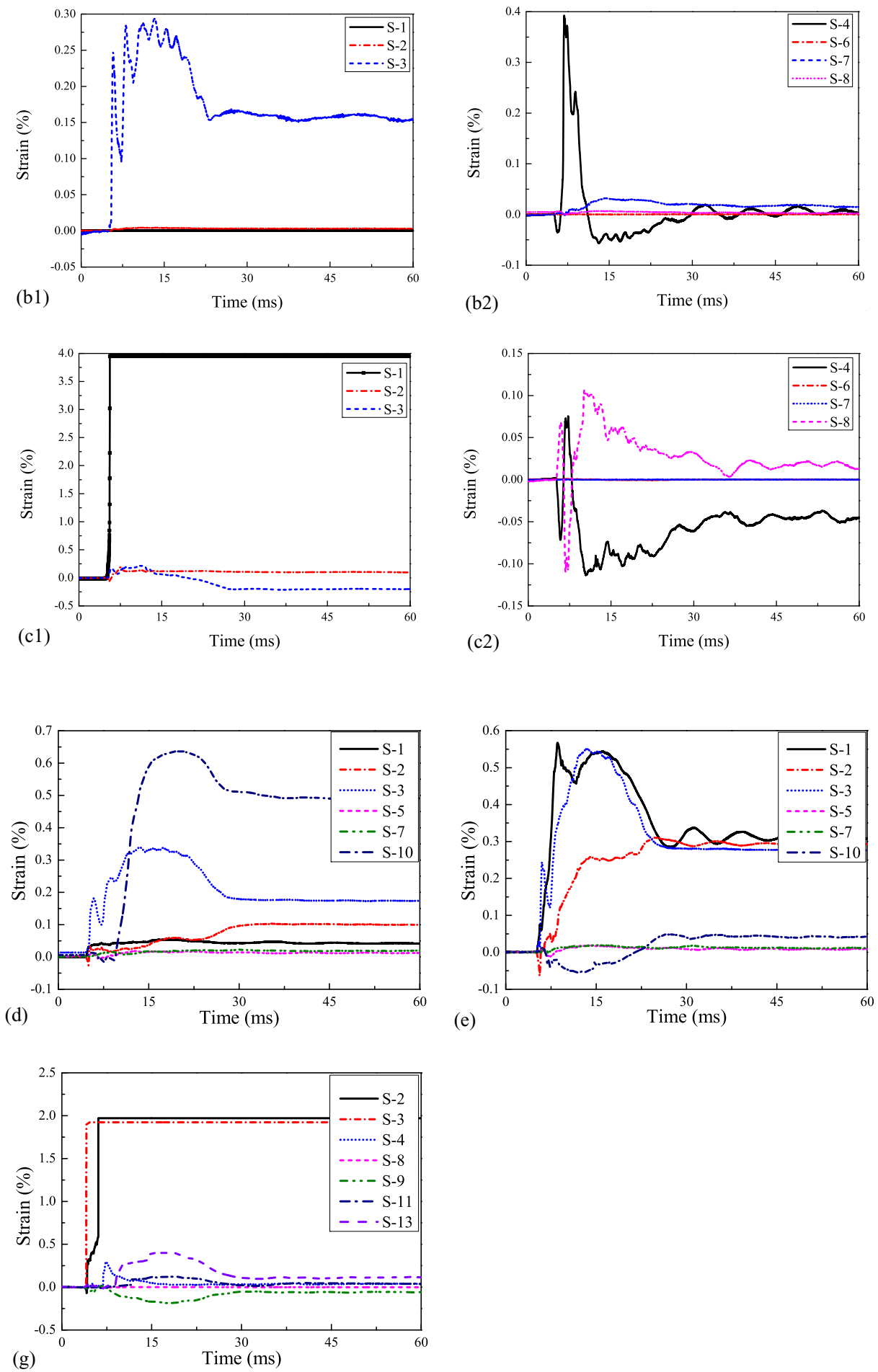

Fig. 12. Strain-time histories: (a) DSTC-1; (b1) DSTC-2: Section A-A; (b2) DSTC-2: Section B-B; (b3) DSTC-2: Section C-C; (c1) DSTC-3: Section A-A; (c2) DSTC-3: Section B-B; (c3) DSTC-3: Section C-C; (d) DSTC-4; (e) DSTC-5; (f) DSTC-6; and (g) DSTC-7.

the midspan region is higher than that at the one-quarter span region. Moreover, when compared to the impact force-time histories, the occurrences of peak acceleration values and peak impact forces are almost simultaneous.

A time lag existed between the two accelerometers, and the time lag indicates the stress wave's travel time from Accelerometer A1 to Accelerometer A2. For UHPC, the theoretical velocity of the elastic wave is $4,400 \mathrm{~m} / \mathrm{s}$ (Yoo et al. 2017). Nevertheless, based on the time lag and the length between the two accelerometers $(0.24 \mathrm{~m})$, the calculated velocity of the stress wave is around
$1,300 \mathrm{~m} / \mathrm{s}$, which is much lower than the theoretical value. Pham and Hao (2016) experimentally studied the lateral impact behavior of FRP strengthened reinforced concrete beams. Based on the obtained data, the calculated velocity of the stress wave was $916 \mathrm{~m} / \mathrm{s}$, which was far less than the theoretical stress wave velocity of NSC (3,300 m/s) (Pham and Hao 2016). It is usually explained that the lower stress wave velocity is caused by the damage of concrete during the impact, which can slow down the stress wave propagation (Pham and Hao 2016; Yoo et al. 2017). Moreover, it is observed that although the theoretical stress wave velocities are 

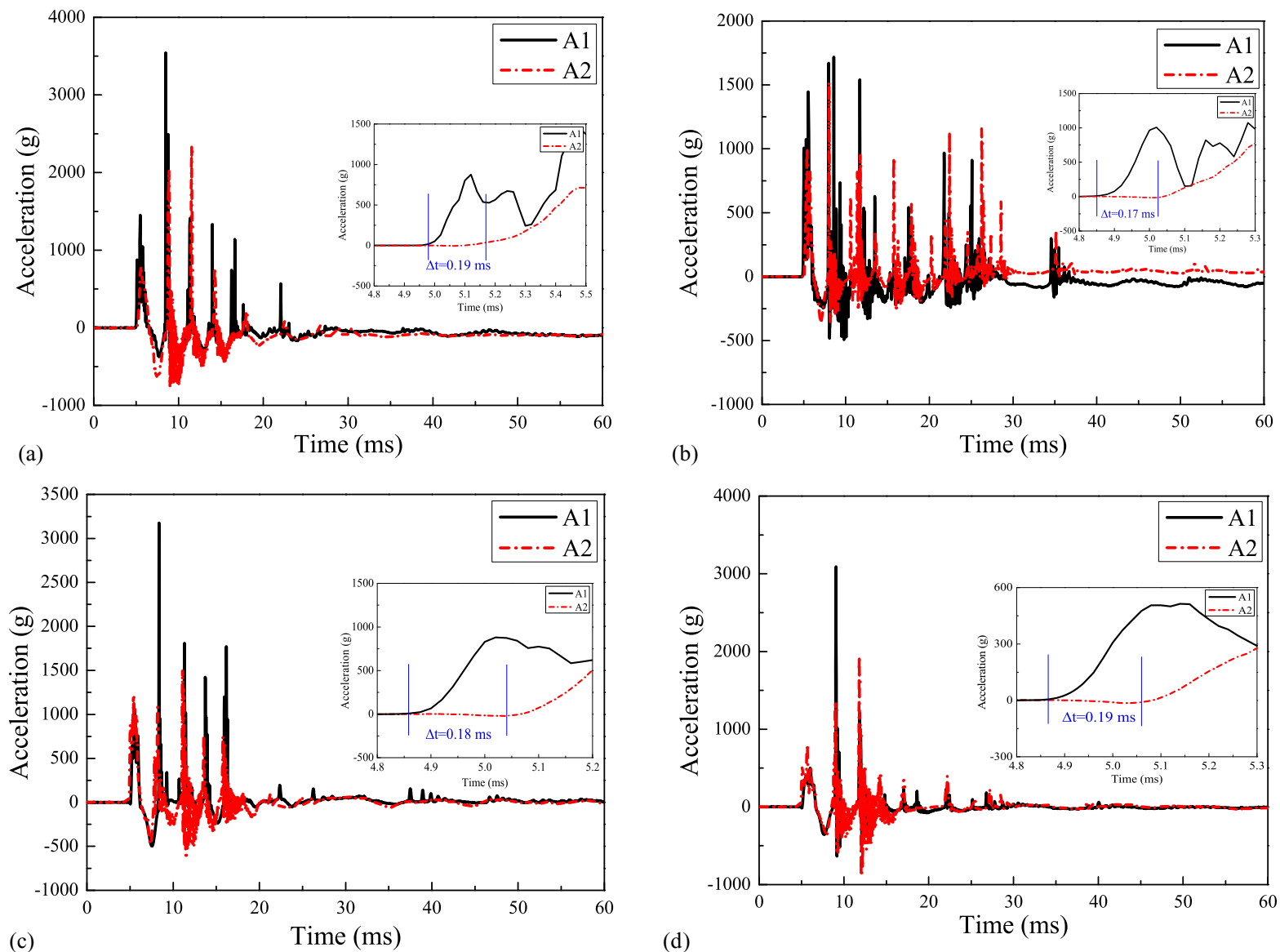

(c)

(d)
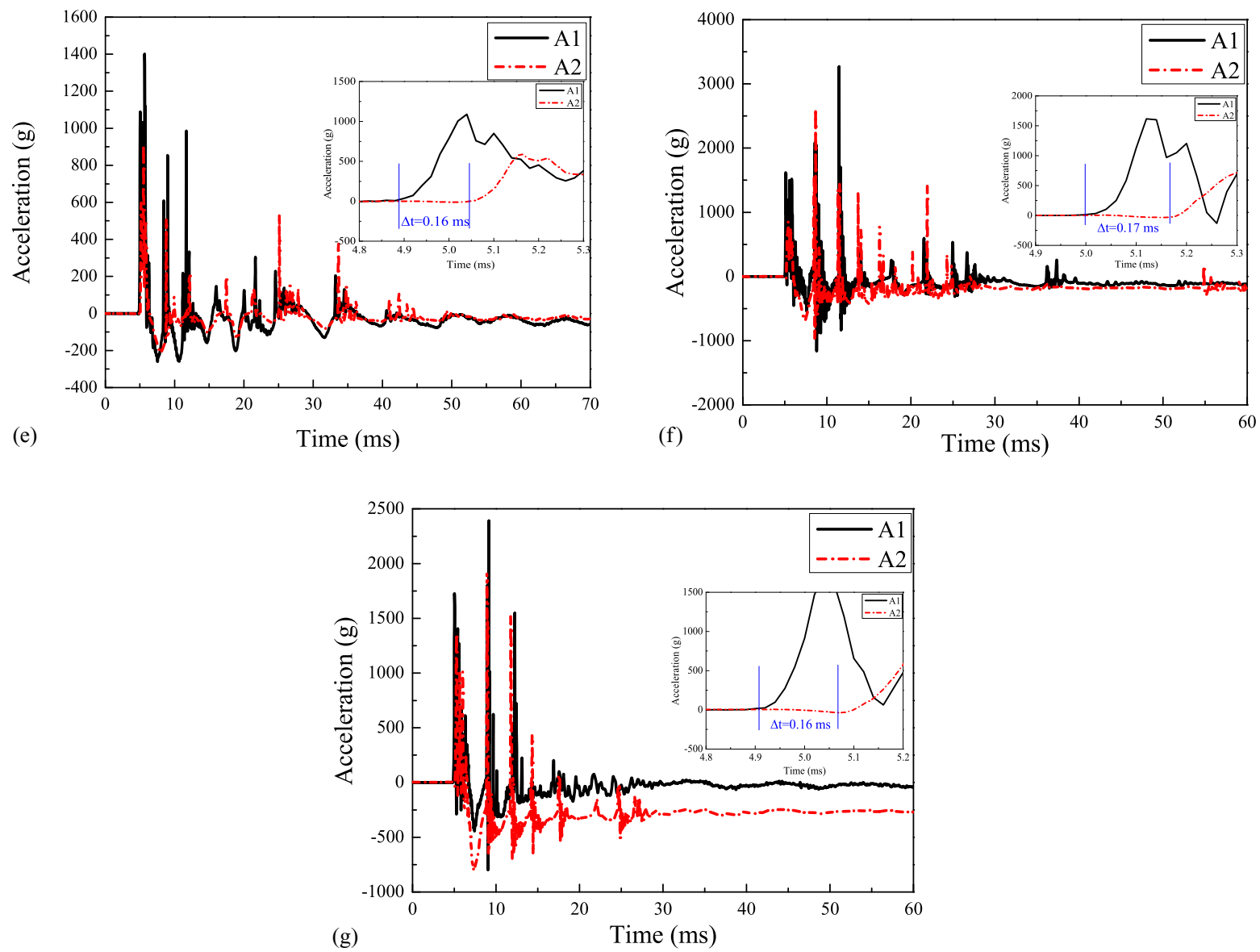

Fig. 13. Acceleration-time histories: (a) DSTC-1; (b) DSTC-2; (c) DSTC-3; (d) DSTC-4; (e) DSTC-5; (f) DSTC-6; and (g) DSTC-7. 


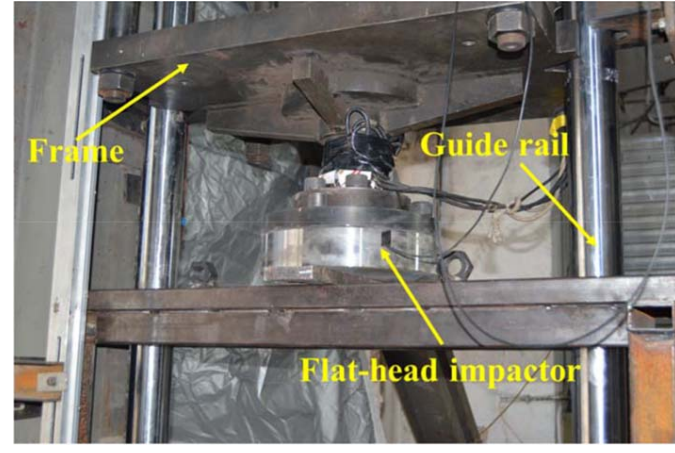

Fig. 14. Flat-head impactor for CFDST and CFST members.

different between UHPC and NSC, their time lags are similar (DSTC-2 and DSTC-4). Due to these uncertainties, the stress wave propagation mechanism during the impact needs to be further investigated.

\section{Comparisons between Hybrid DSTCs, CFDST, and CFST Members}

In this section, comparisons were made between three types of composite columns, namely, the hybrid DSTCs, the concrete-filled double-skin steel tube (CFDST), and the concrete-filled steel tube (CFST) members, on their lateral impact behaviors. More recently, an experimental study has been conducted to investigate the lateral impact behaviors of CFDST and CFST members infilled with UHPC (Wang et al. 2019a). The investigated CFDST and CFST members had a diameter of $168 \mathrm{~mm}$ and a length of 2,000 $\mathrm{mm}$. The same batch of inner steel tubes was used for the hybrid DSTCs in this study and the specimens in Wang et al. (2019a). The outer steel tube had a $168-\mathrm{mm}$ outer diameter and a 5-mm thickness. The average values of the elastic modulus, the yield stress, and the ultimate strength were $206 \mathrm{GPa}, 286$, and $352 \mathrm{MPa}$, respectively. The same drop hammer system was used for these specimens. It is noted that for the CFDST and CFST members, the impactor had a flat head with a 290-mm diameter, as shown in Fig. 14. The selection of the large-sized flat-head impactor was because the load cell in the wedge-shaped impactor was not able to record the peak impact forces of the CFDST and CFST members. Therefore, the selection of different impactors may affect the impact responses of CFDST and CFST members to some extent. The impact height was set to be $4 \mathrm{~m}$ with a corresponding impact energy of $18.85 \mathrm{~kJ}$, and the axial load was not applied. The other experimental setup was the same for the hybrid DSTCs, CFDST, and CFST members.

The midspan $\Delta-t$ histories of hybrid DSTCs, CFDST, and CFST members are presented and compared in Fig. 15. Even though the CFDST and CFST members were impacted under a higher impact energy $(16.86 \mathrm{~kJ})$, their lateral deflections are still smaller than those of Specimen DSTC-3 under an impact energy of $12.64 \mathrm{~kJ}$. The midspan deflection-time histories of CFDST and CFST members are close to those of hybrid DSTCs with an impact energy of $7.37 \mathrm{~kJ}$ (DSTC-2 and DSTC-3). Wang et al. (2019a) numerically investigated the lateral impact resistance contribution from each component of CFDST and CFST members, and it was concluded that the outer steel tube carried a majority of the impact loading in this case, which is mainly because the selection of very thick outer steel tube. The aforementioned experimental observations suggest that when a very thick outer steel tube is used, the CFDST and CFST members exhibit superior lateral impact behaviors than

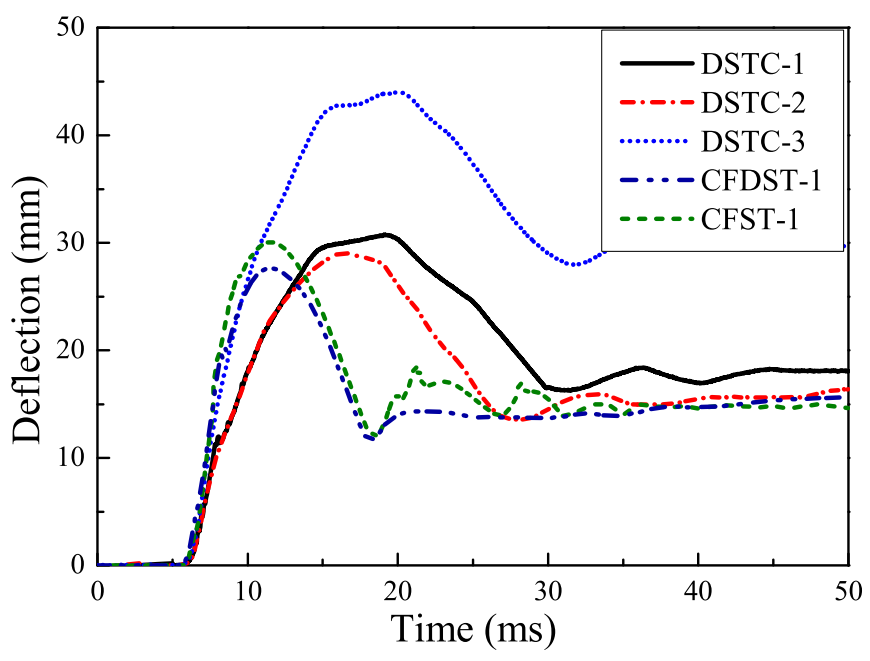

Fig. 15. Comparisons of midspan deflection-time histories.

the hybrid DSTCs. The hybrid DSTCs are a very innovative hybrid concrete member and there is no intention here to be critical of the design. In fact, the aforementioned comparisons are not fair for the hybrid DSTC since some of its advantages cannot be reflected, such as its extraordinary corrosion resistance property. As can be seen in Wang et al. (2019a), the CFDST and CFST members experienced severe corrosion problems shortly after the impact test, while this is not the case for the hybrid DSTCs. Moreover, the main reason for the results differences is the use of a very thick outer steel tube. The outer steel tube had a 5-mm thickness, which was much thicker than the outer FRP tube $(0.5 \mathrm{~mm})$. Therefore, if the outer steel tube thickness is comparable to the outer FRP tube thickness, the differences become insignificant. Furthermore, the design philosophy of the hybrid DSTCs differs from those of CFDST and CFST members. According to the Chinese standard GB 50608 (2012), the suggested void ratio of the hybrid DSTCs should be no less than 0.7 to substantially reduce the amount of concrete, and the lateral impact behavior of hybrid DSTCs can be greatly improved by increasing the void ratio as well as increasing the steel tube thickness (Abdelkarim and ElGawady 2016; Wang et al. 2015).

\section{Conclusions}

This paper experimentally investigated the dynamic responses of hybrid UHPC DSTCs under lateral impact loading. The following conclusions may reach based on the experimental results:

1. The hybrid UHPC DSTCs have a very ductile response under lateral impact. Compared to the hybrid DSTCs with normalstrength concrete, the hybrid UHPC DSTCs have higher lateral impact resistance capacity, such as higher peak/plateau impact force, smaller impact duration, and lower lateral deflection.

2. The existence of $200-\mathrm{kN}$ axial force is beneficial to improve the lateral impact behavior of hybrid UHPC DSTCs. Moreover, with a higher impact energy, the lateral deflection and the duration can be increased. Nevertheless, the change of plateau impact force is insignificant by increasing the impact energy.

3. The peak impact force and the lateral deflection significantly decrease with an increase in the void ratio, while the plateau impact force increases to some extent. Although the FRP tube does not contribute to the lateral impact resistance directly, it can improve the lateral impact behavior of hybrid UHPC DSTCs by providing external confinement and shear resistance. 
The thicker the FRP tube, the higher the lateral impact resistance capacity.

4. Comparisons between the hybrid DSTCs, CFDST, and CFST members indicate that with a thick outer steel tube, the hybrid DSTCs may exhibit moderate performance as compared to the CFDST and CFST members. Nevertheless, due to the different design philosophy of hybrid DSTCs, the lateral impact resistance capacity of hybrid DSTCs can be significantly increased by increasing the void ratio as well as the inner steel tube thickness.

\section{Data Availability Statement}

All data, models, or code generated or used during the study are available from the corresponding author by request.

\section{Acknowledgments}

The authors would like to acknowledge Professors Feng Fan and Xudong Zhi, Harbin Institute of Technology, for their help in carrying out the experiment program. The technical assistances from Drs Rong Zhang, Qijian Wu, and Menghui Guo are greatly appreciated. Moreover, the authors acknowledge the financial support from the China National Basic Research Program (No. 2015CB058002) and the ARC Discovery Project (No. DP160104661).

\section{References}

Abdelkarim, O. I., and M. A. ElGawady. 2016. "Performance of hollowcore FRP-concrete-steel bridge columns subjected to vehicle collision." Eng. Struct. 123: 517-531. https://doi.org/10.1016/j.engstruct 2016.05.048

ACI (American Concrete Institute). 2017. Guide for the design and construction of externally bonded FRP systems for strengthening concrete structures. ACI 440.2R. Farmington Hills, MI: ACI.

AS (Australian Standard). 2014. Methods of testing concrete-Method 9: Determination of the compressive strength of concrete specimens. AS 1012.9. Sydney, NSW, Australia: AS.

ASTM. 2010. Standard test method for determining tensile properties of fibre reinforced polymer matrix composites used for strengthening of civil structures. ASTM D7565/D7565M. West Conshohocken, PA: ASTM.

Belzer, B. E., M. J. Robinson, and D. R. Fick. 2013. "Composite action of concrete-filled rectangular GFRP tubes.” J. Compos. Constr. 17 (5): 722-731. https://doi.org/10.1061/(ASCE)CC.1943-5614.0000370.

Fam, A. Z., and S. H. Rizkalla. 2001. "Behavior of axially loaded concretefilled circular fiber-reinforced polymer tubes.” ACI Struct. J. 98 (3): 280-289.

Fan, W., D. Shen, T. Yang, and X. Shao. 2019. "Experimental and numerical study on low-velocity lateral impact behaviors of RC, UHPFRC and UHPFRC-strengthened columns." Eng. Struct. 191: 509-525. https://doi.org/10.1016/j.engstruct.2019.04.086.

GB Standard (Guobiao Standard). 2012. Technical code for infrastructure application of FRP composites. GB 50608. Beijing: China Architecture and Building Press.

Gholipour, G., C. Zhang, and A. A. Mousavi. 2018. "Effects of axial load on nonlinear response of RC columns subjected to lateral impact load: Ship-pier collision." Eng. Fail. Anal. 91: 397-418. https://doi.org/10 .1016/j.engfailanal.2018.04.055.

Gurbuz, T., A. Ilki, D. P. Thambiratnam, and N. Perera. 2019. "Low-elevation impact tests of axially loaded reinforced concrete columns." ACI Struct. J. 116 (1): 117-128. https://doi.org/10.14359 /51710862.
Hannawi, K., H. Bian, W. Prince-Agbodjan, and B. Raghavan. 2016. "Effect of different types of fibers on the microstructure and the mechanical behavior of ultra-high performance fiber-reinforced concretes." Compos. Part B: Eng. 86: 214-220. https://doi.org/10.1016/j .compositesb.2015.09.059.

Hou, C.-C., L.-H. Han, F.-C. Wang, and C.-M. Hu. 2019. "Study on the impact behaviour of concrete-encased CFST box members." Eng. Struct. 198: 109536. https://doi.org/10.1016/j.engstruct.2019.109536.

Idris, Y., and T. Ozbakkaloglu. 2016. "Behavior of square fiber reinforced polymer-high-strength concrete-steel double-skin tubular columns under combined axial compression and reversed-cyclic lateral loading." Eng. Struct. 118: 307-319. https://doi.org/10.1016/j .engstruct.2016.03.059

Lam, L., and J. G. Teng. 2003. "Design-oriented stress-strain model for FRP-confined concrete." Constr. Build. Mater. 17 (6-7): 471-489. https://doi.org/10.1016/S0950-0618(03)00045-X.

Magureanu, C., I. Sosa, C. Negrutiu, and B. Heghes. 2012. "Mechanical properties and durability of ultra-high-performance concrete." $A C I$ Mater. J. 109 (2): 177-184.

Mohamed, H. M., and R. Masmoudi. 2010. "Axial load capacity of concrete-filled FRP tube columns: Experimental versus theoretical predictions." J. Compos. Constr. 14 (2): 231-243. https://doi.org/10.1061 /(ASCE)CC.1943-5614.0000066.

Nanjing Hitech Composites. 2015. "Dongping Industrial Park, Lishui, Nanjing, Jiangsu Province, China." Accessed July, 2015. http://www .hitechfrp.com/haituo/indexyw.asp/.

Othman, H., and H. Marzouk. 2018. "Applicability of damage plasticity constitutive model for ultra-high performance fibre-reinforced concrete under impact loads." Int. J. Impact Eng. 114: 20-31. https://doi.org/10 .1016/j.ijimpeng.2017.12.013.

Ozbakkaloglu, T., and B. L. Fanggi. 2014. "Axial compressive behavior of FRP-concrete-steel double-skin tubular columns made of normal- and high-strength concrete." J. Compos. Constr. 18 (1): 04013027. https://doi.org/10.1061/(ASCE)CC.1943-5614.0000401.

Ozbakkaloglu, T., and B. A. Louk Fanggi. 2015. "FRP-HSC-steel composite columns: Behavior under monotonic and cyclic axial compression." Mater. Struct. 48 (4): 1075-1093. https://doi.org/10.1617/s11527-013 -0216-0.

Ozbakkaloglu, T., and Y. Idris. 2014. "Seismic behavior of FRP-highstrength concrete-steel double-skin tubular columns." J. Struct. Eng. 140 (6): 04014019. https://doi.org/10.1061/(ASCE)ST.1943-541X .0000981

Pham, T. M., and H. Hao. 2016. "Impact behavior of FRP-strengthened RC beams without stirrups." J. Compos. Constr. 20 (4): 04016011. https://doi.org/10.1061/(ASCE)CC.1943-5614.0000671.

Shi, C., Z. Wu, J. Xiao, D. Wang, Z. Huang, and Z. Fang. 2015. “A review on ultra high performance concrete: Part I. Raw materials and mixture design.” Constr. Build. Mater. 101: 741-751. https://doi.org/10.1016/j .conbuildmat.2015.10.088

Teng, J. G., T. Jiang, L. Lam, and Y. Z. Luo. 2009. "Refinement of a design-oriented stress-strain model for FRP-confined concrete." J. Compos. Constr. 13 (4): 269-278. https://doi.org/10.1061/(ASCE) CC.1943-5614.0000012.

Teng, J. G., T. Yu, Y. L. Wong, and S. L. Dong. 2007. "Hybrid FRP-concrete-steel tubular columns: Concept and behavior." Constr. Build. Mater. 21 (4): 846-854. https://doi.org/10.1016/j.conbuildmat .2006.06.017.

Thilakarathna, H. M. I., D. P. Thambiratnam, M. Dhanasekar, and N. Perera. 2010. "Numerical simulation of axially loaded concrete columns under transverse impact and vulnerability assessment." Int. J. Impact Eng. 37 (11): 1100-1112. https://doi.org/10.1016/j .ijimpeng.2010.06.003

Tran, N. T., T. K. Tran, and D. J. Kim. 2015. "High rate response of ultra-high-performance fiber-reinforced concretes under direct tension." Cem. Concr. Res. 69: 72-87. https://doi.org/10.1016/j.cemconres.2014 .12.008.

Wang, R., L.-H. Han, and Z. Tao. 2015. "Behavior of FRP-concrete-steel double skin tubular members under lateral impact: Experimental study." Thin-Walled Struct. 95: 363-373. https://doi.org/10.1016/j.tws.2015.06 .022 . 
Wang, W., P. R. Martin, M. N. Sheikh, and M. N. S. Hadi. 2018 a. "Eccentrically loaded FRP confined concrete with different wrapping schemes." J. Compos. Constr. 22 (6): 04018056. https://doi.org/10 .1061/(ASCE)CC.1943-5614.0000898.

Wang, W., M. N. Sheikh, and M. N. S. Hadi. 2016. "Experimental study on FRP tube reinforced concrete columns under different loading conditions." J. Compos. Constr. 20 (5): 04016034. https://doi.org/10.1061 /(ASCE)CC.1943-5614.0000690.

Wang, W., M. N. Sheikh, M. N. S. Hadi, D. Gao, and G. Chen. 2017a. "Behaviour of concrete-encased concrete-filled FRP tube (CCFT) columns under axial compression." Eng. Struct. 147: 256-268. https://doi.org/10.1016/j.engstruct.2017.05.061.

Wang, W., C. Wu, and J. Li. 2018b. "Numerical simulation of hybrid FRP-concrete-steel double-skin tubular columns under close-range blast loading." J. Compos. Constr. 22 (5): 04018036. https://doi.org /10.1061/(ASCE)CC.1943-5614.0000871.

Wang, W., C. Wu, J. Li, Z. Liu, and Y. Lv. 2019a. "Behavior of ultra-high performance fiber-reinforced concrete (UHPFRC) filled steel tubular members under lateral impact loading." Int. J. Impact Eng. 132: 103314. https://doi.org/10.1016/j.ijimpeng.2019.103314.

Wang, W., C. Wu, and Z. Liu. 2019b. "Compressive behavior of hybrid double-skin tubular columns with ultra-high performance fiberreinforced concrete (UHPFRC)." Eng. Struct. 180: 419-441. https://doi.org/10.1016/j.engstruct.2018.11.048.

Wang, W., C. Wu, Z. Liu, and H. Si. 2018c. "Compressive behavior of ultra-high performance fiber-reinforced concrete (UHPFRC) confined with FRP." Compos. Struct. 204: 419-437. https://doi.org/10.1016/j compstruct.2018.07.102.

Wang, X., C. Demartino, J. Xu, and Y. Xiao. 2017b. "Dynamic response of concrete filled steel tube column under lateral impact load: Experimental study and calculation method." China Civ. Eng. J. 50 (12): 28-36. https://doi.org/10.3901/JME.2017.20.028.

Wei, J., J. Li, and C. Wu. 2019. "An experimental and numerical study of reinforced conventional concrete and ultra-high performance concrete columns under lateral impact loads.” Eng. Struct. 201: 109822. https://doi.org/10.1016/j.engstruct.2019.109822.

Wille, K., S. El-Tawil, and A. E. Naaman. 2014. "Properties of strain hardening ultra high performance fiber reinforced concrete (UHP-FRC) under direct tensile loading." Cem. Concr. Compos. 48: 53-66. https://doi.org/10.1016/j.cemconcomp.2013.12.015.

Wong, Y. L., T. Yu, J. G. Teng, and S. L. Dong. 2008. "Behavior of FRP-confined concrete in annular section columns." Compos. Part B: Eng. 39 (3): 451-466. https://doi.org/10.1016/j.compositesb.2007.04 .001 .

Wu, Z., C. Shi, W. He, and L. Wu. 2016. "Effects of steel fiber content and shape on mechanical properties of ultra high performance concrete." Constr. Build. Mater. 103: 8-14. https://doi.org/10.1016/j .conbuildmat.2015.11.028.
Yoo, D.-Y., and N. Banthia. 2016. "Mechanical properties of ultra-high-performance fiber-reinforced concrete: A review." Cem. Concr. Compos. 73: 267-280. https://doi.org/10.1016/j.cemconcomp 2016.08.001

Yoo, D. Y., N. Banthia, S. W. Kim, and Y. S. Yoon. 2015. "Response of ultra-high-performance fiber-reinforced concrete beams with continuous steel reinforcement subjected to low-velocity impact loading." Compos. Struct. 126: 233-245. https://doi.org/10.1016/j.compstruct .2015.02.058

Yoo, D. Y., N. Banthia, and Y. S. Yoon. 2017. "Impact resistance of reinforced ultra-high-performance concrete beams with different steel fibers." ACI Struct. J. 114 (1): 113-124.

Yu, T., and J. G. Teng. 2011. "Design of concrete-filled FRP tubular columns: Provisions in the Chinese technical code for infrastructure application of FRP composites." J. Compos. Constr. 15 (3): 451-461. https://doi.org/10.1061/(ASCE)CC.1943-5614.0000159.

Yu, T., J. G. Teng, and Y. L. Wong. 2010. "Stress-strain behavior of concrete in hybrid FRP-concrete-steel double-skin tubular columns." J. Struct. Eng. 136 (4): 379-389. https://doi.org/10.1061/(ASCE)ST .1943-541X.0000121.

Zeng, J.-J., W.-Y. Gao, Z.-J. Duan, Y.-L. Bai, Y.-C. Guo, and L.-J. Ouyang. 2020a. "Axial compressive behavior of polyethylene terephthalate/carbon FRP-confined seawater sea-sand concrete in circular columns." Constr. Build. Mater. 234: 117383. https://doi.org/10.1016 /j.conbuildmat.2019.117383

Zeng, J. J., G. Lin, J. G. Teng, and L. J. Li. 2018. "Behavior of large-scale FRP-confined rectangular RC columns under axial compression." Eng. Struct. 174: 629-645. https://doi.org/10.1016/j.engstruct.2018.07.086.

Zeng, J.-J., Y.-Y. Ye, Y.-C. Guo, J.-F. Lv, Y. Ouyang, and C. Jiang. 2020b. "PET FRP-concrete-high strength steel hybrid solid columns with strain-hardening and ductile performance: Cyclic axial compressive behavior." Compos. Part B: Eng. 190: 107903. https://doi.org/10.1016/j compositesb.2020.107903.

Zhang, B., J. G. Teng, and T. Yu. 2015. "Experimental behavior of hybrid FRP-concrete-steel double-skin tubular columns under combined axial compression and cyclic lateral loading." Eng. Struct. 99: 214-231. https://doi.org/10.1016/j.engstruct.2015.05.002.

Zhang, B., J. G. Teng, and T. Yu. 2017. "Compressive behavior of doubleskin tubular columns with high-strength concrete and a filament-wound FRP tube.” J. Compos. Constr. 21 (5): 04017029. https://doi.org/10 .1061/(ASCE)CC.1943-5614.0000800.

Zhao, J. L., J. G. Teng, T. Yu, and L. J. Li. 2016. "Behavior of large-scale hybrid FRP-concrete-steel double-skin tubular beams with shear connectors." J. Compos. Constr. 20 (5): 04016015. https://doi.org/10 1061/(ASCE)CC.1943-5614.0000669.

Zhi, X. D., R. Zhang, F. Fan, and C. Huang. 2018. "Experimental study on axially preloaded circular steel tubes subjected to low-velocity transverse impact." Thin-Walled Struct. 130: 161-175. https://doi.org/10 .1016/j.tws.2018.05.025 